OPEN ACCESS

Edited by:

Tamas Zakar,

The University of Newcastle, Australia

Reviewed by:

Adam John Watkins,

University of Nottingham,

United Kingdom

Hieu D. Hoang,

Columbia University, United States

${ }^{*}$ Correspondence:

Murray D. Mitchell

murray.mitchel॥qut.edu.au

Specialty section:

This article was submitted to Embryonic and Developmental Physiology,

a section of the journal

Frontiers in Physiology

Received: 13 August 2020 Accepted: 03 November 2020 Published: 23 December 2020

Citation:

Mosaad E, Peiris HN, Holland O, Morean Garcia I and Mitchell MD (2020) The Role(s) of Eicosanoids and Exosomes in Human Parturition.

Front. Physiol. 11:594313.

doi: 10.3389/fphys.2020.594313

\section{The Role(s) of Eicosanoids and Exosomes in Human Parturition}

\author{
Eman Mosaad ${ }^{1}$, Hassendrini N. Peiris ${ }^{1}$, Olivia Holland ${ }^{1,2}$, Isabella Morean Garcia ${ }^{1}$ and \\ Murray D. Mitchell ${ }^{*}$
}

\begin{abstract}
'School of Biomedical Science, Institute of Health and Biomedical Innovation - Centre for Children's Health Research, Faculty of Health, Queensland University of Technology, Brisbane, QLD, Australia, ${ }^{2}$ School of Medical Science, Griffith University, Southport, QLD, Australia
\end{abstract}

The roles that eicosanoids play during pregnancy and parturition are crucial to a successful outcome. A better understanding of the regulation of eicosanoid production and the roles played by the various end products during pregnancy and parturition has led to our view that accurate measurements of a panel of those end products has exciting potential as diagnostics and prognostics of preterm labor and delivery. Exosomes and their contents represent an exciting new area for research of movement of key biological factors circulating between tissues and organs akin to a parallel endocrine system but involving key intracellular mediators. Eicosanoids and enzymes regulating their biosynthesis and metabolism as well as regulatory microRNAs have been identified within exosomes. In this review, the regulation of eicosanoid production, abundance and actions during pregnancy will be explored. Additionally, the functional significance of placental exosomes will be discussed.

Keywords: exosomes, eicosanoids, prostaglandins, pregnancy, parturition, gestation, preterm labor

\section{INTRODUCTION}

The fetal membranes perform unique functions to support fetal development and respond to signals for parturition. The correct timing for triggering this process is critical for the successful outcome of the pregnancy. The parturition process is mediated by a combination of signals from the fetus, placenta and mother. There are mainly two signallers of parturition that are interdependent and well reported, namely fetal endocrine signals and fetal growth-related signals (Challis et al., 2005; Menon, 2016; Mesiano, 2019). Both pathways directly and indirectly induce higher production of eicosanoids (particularly prostaglandins) which are important signaling molecules that affect the contractile activity of the myometrium leading to parturition (Challis et al., 2005; Reinl and England, 2015). Hence, administration of specific prostaglandins $\left(\mathrm{E}_{2}\right.$ or $\left.\mathrm{F}_{2 \alpha}\right)$ is proven to effectively induce labor and cervical ripening $\left(\mathrm{E}_{2}\right)$ in women. Additionally, a better understanding of the

Abbreviations: 5-LOX, 5-lipoxygenase; BLT1-2, Leukotriene B4 receptor 1-2; cAMP, Cyclic AMP; COX, Cyclooxygenase; $C R H$, Corticotrophin-releasing hormone; CysLT1-2, Cysteinyl leukotriene receptor 1-2; DP1-2, Prostaglandin $\mathrm{D}_{2}$ receptor 1-2; EETs, Epoxy-eicosatrienoic acids; EP1-4, Prostaglandin E2 receptor 1-4; ESCRT, Endosomal Sorting Complexes for Transport; $E V s$, Extracellular vesicles; FLAP, Five-lipoxygenase activating protein; FP, Prostaglandin $\mathrm{F}_{2 \alpha}$ receptor; GRO $\alpha$, Growth-related oncogene- $\alpha$; HETEs, Hydroxy-eicosatetraenoic acids; HPETE, Hydroperoxyl eicosatetraenoic acid; $I L$, Interleukin; $I L V s$, Intraluminal vesicles; $I P$, Prostaglandin $\mathrm{I}_{2}$ receptor; $L T A_{4}$, Leukotriene $\mathrm{A}_{4} ; L T B_{4}$, Leukotriene $\mathrm{B}_{4}$; $L T C_{4}$, Leukotriene $\mathrm{C}_{4} ; L T D_{4}$, Leukotriene $\mathrm{D}_{4}$; LTs, Leukotrienes; MRPs, Multidrug-resistance proteins; MTOC, Microtubule organization center; $M V B$, Multivesicular Bodies; $P G$, Prostaglandin; $P G D_{2}$, Prostaglandin $D_{2} ; P G D H$, prostaglandin dehydrogenase; $P G E_{2}$, Prostaglandin $\mathrm{E}_{2} ; P G F_{2 \alpha}$, Prostaglandin $\mathrm{F}_{2 \alpha} ; P G H_{2}$, Prostaglandin $\mathrm{H}_{2} ; P G H S=P T G S-2$, prostaglandin endoperoxide synthase-2; $P G I_{2}$, Prostaglandin $\mathrm{I}_{2} ; T N F \alpha$, Tumor necrosis factor- $\alpha$; TP, Thromboxane receptor; $T X A_{2}$, Thromboxane $\mathrm{A}_{2}$. 
regulation of eicosanoid production and the roles played by the various end products during pregnancy and parturition has led to our view that accurate measurements of a panel of those end products has exciting potential as diagnostics and prognostics of preterm labor and delivery (Mitchell et al., 2015).

In this review, we explore the roles and distribution of eicosanoids in the human uterus and fetal membrane during parturition. We also describe exosome abundance during pregnancy and parturition. Finally, we discuss the potentially pivotal role of exosomes in distributing eicosanoids and the related diagnostic and therapeutic potential that this brings.

\section{EICOSANOIDS}

The term "eicosanoid" has evolved overtime as a definitive term for products of a family of polyunsaturated $\left(\mathrm{C}_{20}\right)$ fatty acids; including, but not limited to, lipoxins, leukotrienes, thromboxanes and prostaglandins. The biosynthesis of eicosanoids and their structural properties are well characterized in mammals (Smith, 1989). Eicosanoids are not stored, and their biosynthesis occurs in all mammalian tissues as a response to hormonal stimulation or mechanical trauma, acting as paracrine or autocrine modulators (Esser-von Bieren, 2017; Strauss and FitzGerald, 2019). Their actions are mediated by the activation of membrane receptors (Kim and Luster, 2007).

\section{Eicosanoid Biosynthesis}

A first essential and usually rate limiting step in eicosanoid biosynthesis is release of polyunsaturated $\left(\mathrm{C}_{20}\right)$ fatty acids from membrane phospholipid stores (Fitzpatrick and Soberman, 2001). Arachidonic acid is the major common precursor of eicosanoids and its release is precisely regulated by several types of phospholipase $A_{2}$ (Burke and Dennis, 2009) or phospholipase $\mathrm{C}$ and subsequent mono- and diacylglycerol lipases (Kano et al., 2009; Hanna and Hafez, 2018). Once released arachidonic acid is converted enzymatically to various eicosanoids via three main pathways (Figure 1): namely, the cyclooxygenase pathway, the lipoxygenase pathway, and the cytochrome P-450 epoxygenase pathway (Strauss and FitzGerald, 2019).

The major products of the cyclooxygenase (COX) pathway are prostanoids such as prostaglandins, thromboxanes and prostacyclin. There are two major COX enzymes that initiate the synthesis of prostaglandins, COX-1 is mainly expressed constitutively, and COX-2 is often induced via cytokines, growth factors and hormones (Herschman, 1996; Smith et al., 1996). Prostaglandin $\mathrm{H}_{2}\left(\mathrm{PGH}_{2}\right)$, a direct product of arachidonic acid release and reaction to COX enzymes, is converted to individual prostanoids that are tissue specific by the action of corresponding isomerases and synthases (Smith et al., 2000). For instance, thromboxane $\mathrm{A}_{2}\left(\mathrm{TXA}_{2}\right)$ synthase is expressed in platelets and macrophages; prostaglandin $\mathrm{I}_{2}\left(\mathrm{PGI}_{2}\right)$, also known as prostacyclin, synthase is expressed in endothelial cells and prostaglandin $\mathrm{F}_{2 \alpha}\left(\mathrm{PGF}_{2 \alpha}\right)$ synthase is abundant in the uterus $(\mathrm{Ni}$ et al., 2003; Ueno et al., 2005).

The lipoxygenase pathway produces leukotrienes (LTs). Products of this pathway in leukocytes are part of the LT family of lipid mediators, whose synthesis is mainly initiated by inflammatory cells. Formation of LTs is initiated via hydroperoxyl eicosatetraenoic acid (HPETE) formation from arachidonic acid by 5 -lipoxygenase (5-LOX). 5-LOX in turn requires the cooperation of an accessory protein known as five-lipoxygenase activating protein (FLAP). Most HPETE molecules are converted to leukotriene A4 $\left(\mathrm{LTA}_{4}\right) . \mathrm{LTA}_{4}$ can serve in vitro as a precursor for the transcellular biosynthesis of lipoxins and can undergo multiple routes of transformation (Bäck et al., 2011).

The cytochrome P450 epoxygenase pathway produces mainly epoxy-eicosatrienoic acids (EETs) via the catalysis of monooxygenation of arachidonic acid (Smith, 1989; Strauss and FitzGerald, 2019). However, hydroxygenases can also convert arachidonic acid to hydroxy-eicosatetraenoic acids (HETEs) (Strauss and FitzGerald, 2019).

\section{Transport and Function}

Despite the lipid nature of eicosanoids, they do not penetrate the cell membrane freely. Efflux transporters, such as multidrugresistance proteins (MRPs), are necessary to transport newly synthesized eicosanoids outside the manufacturing cells. Additionally, the cellular uptake of eicosanoids is regulated by organic anion transporter proteins (Funk, 2001). The abundance of eicosanoid receptors and transporters is a limiting factor for their action. Therefore, they are believed to act as local or paracrine effectors initiating specific biochemical reactions in certain tissues.

Due to the different mechanisms that eicosanoids can induce on the cellular level, there are discrete receptor for each compound that mediate its action within the cell (Olson and Ammann, 2007). Thus far, there are 13 distinct cloned and characterized receptors for eicosanoids, including nine for cyclooxygenase-derived prostanoids and four for lipoxygenase-derived leukotrienes (Funk, 2001; Narumiya and Furuyashiki, 2011; Woodward et al., 2011). The nine prostanoid receptors mediate eicosanoid actions via cyclic AMP (cAMP), phosphatidylinositol turnover and $\mathrm{Ca}^{2+}$ shifts (Table 1).

Despite the short lifespan of eicosanoids, their biological effects are robust. Their biological properties have been studied in many contexts such as the cardiovascular system, immune system, nervous system and gastrointestinal tract as well as in inflammatory settings (Strauss and FitzGerald, 2019). The roles of eicosanoids in reproductive physiology are extensively studied in seminal fluid (Samuelsson, 1963; Alexandre et al., 2007; Remes Lenicov et al., 2012; Szczykutowicz et al., 2019), luteolytic actions (Vijayakumar and Walters, 1983; Bennegård et al., 1991; Miceli et al., 2001) and uterine physiology in pregnancy (Peiris et al., 2017); however, the roles of specific eicosanoids are still being elucidated. In the following sections, we will focus on the role of eicosanoids in uterine physiology during pregnancy and parturition.

\section{Eicosanoids in Pregnancy and Parturition}

The strong relationship between eicosanoids and pregnancy has been recognized for many years. Eicosanoids have various roles 


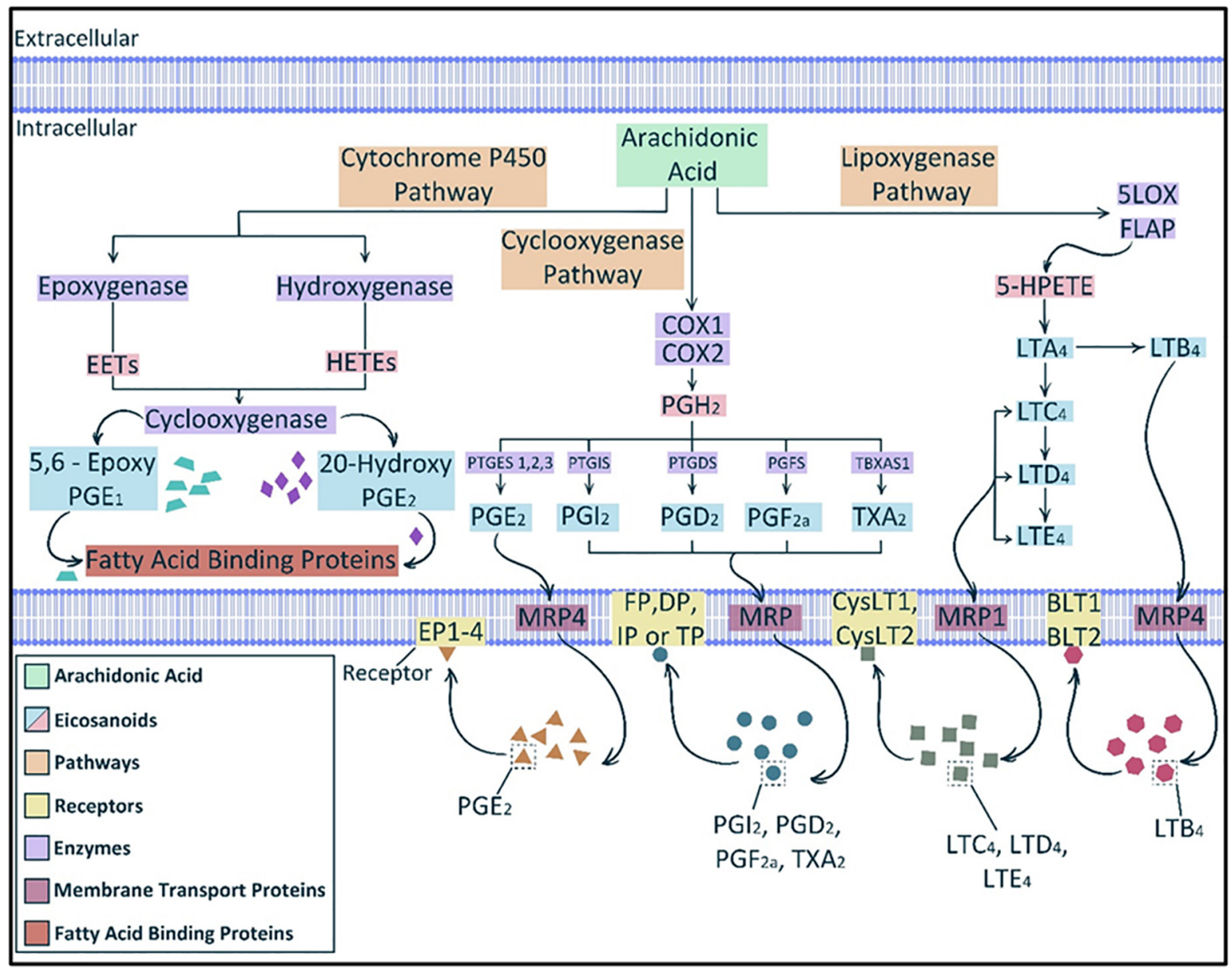

FIGURE 1 | Eicosanoid biosynthesis. The main three pathways involved in eicosanoids biosynthesis from the main precursor, arachidonic acid, are lipoxygenase, cyclooxygenase and cytochrome P450 pathways. The cytochrome P450 pathway produces epoxyeicosatrienoic acids (EETs) and hydroxyeicosatetraenoic acids (HETEs) from which some products can be further metabolized by cyclooxygenase. Cyclooxygenases (COX1 and 2) can act directly on arachidonic acid to produce the unstable intermediate prostaglandin $(\mathrm{PG}) \mathrm{H}_{2}\left(\mathrm{PGH}_{2}\right)$ which then can produce various prostanoids such as $\mathrm{PGE}_{2}, \mathrm{PG}_{2}, \mathrm{PGD}_{2}$, and $\mathrm{PGF}_{2 \alpha}$ and thromboxane $\mathrm{A}_{2}$ $\left(T_{X} A_{2}\right)$. Lipoxygenase pathway yields leukotrienes (LTs), such as $\mathrm{LTA}_{4}$ and $\mathrm{LTB}_{4}$. Multidrug resistant proteins (MRPs) facilitate the transfer of eicosanoids through the cell membrane. Multiple cellular membrane receptors mediate the action of eicosanoids, such as EP1-4 for PGE 2 and BLT1-2 for LTB . [After (Funk, 2001; Strauss and FitzGerald, 2019)].

TABLE 1 | Eicosanoid receptors and their functional properties.

\begin{tabular}{llll}
\hline Eicosanoid category & Ligand & Receptor & Functional properties \\
\hline Cyclooxygenase pathway (prostanoids) & $\mathrm{TXA}_{2}$ & $\mathrm{TP}$ & Increase intracellular calcium, Contractile \\
& $\mathrm{PG}_{2}$ & $\mathrm{IP}$ & Increase intracellular cAMP, Relaxing \\
& $\mathrm{PGFzOC}$ & $\mathrm{FP}$ & Increase intracellular calcium, Contractile \\
& $\mathrm{PGD}_{2}$ & $\mathrm{DPI}$ & Increase intracellular cAMP, Relaxing \\
& $\mathrm{PGE}_{2}$ & $\mathrm{DP} 2$ & Induce intracellular calcium mobilization and chemoattractant \\
& & $\mathrm{EP1}$ & Increase intracellular calcium, Contractile \\
Lipoxygenase pathway (leukotrienes) & $\mathrm{EP3}$ & Inhibit cAMP production, Inhibitory \\
& $\mathrm{LTB}_{4}$ & $\mathrm{BLT1}$ BLT2 & Increase intracellular cAMP, Relaxing \\
& $\mathrm{LTD}_{4}$ & Induce intracellular calcium mobilization and inhibit cAMP production \\
$\mathrm{LTC}_{4}, \mathrm{LTD}_{4}$ & CysLT2 & Increase intracellular calcium
\end{tabular}

BLT1 -2: Leukotriene $B_{4}$ receptor 1-2; CAMP: Cyclic AMP; CysLT1-2: Cysteinyl leukotriene receptor 1-2; DP1-2: Prostaglandin $D_{2}$ receptor 1-2; EP1-4: Prostaglandin E 2

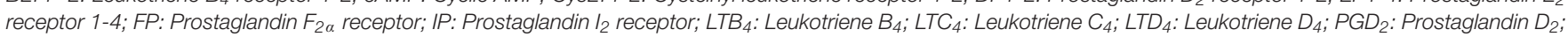
$\mathrm{PGE}_{2}$ : Prostaglandin $\mathrm{E}_{2} ; \mathrm{PGF}_{2 \alpha}$ : Prostaglandin $\mathrm{F}_{2 \alpha} ; \mathrm{PGl}_{2}$ : Prostaglandin $\mathrm{I}_{2}$; TP: Thromboxane receptor; $T X \mathrm{~A}_{2}$ : Thromboxane $\mathrm{A}_{2}$. 
in the reproduction process, including ovulation, corpus luteum function, luteolysis, fertilization and decidualisation as well as parturition as previously reviewed (Strauss and FitzGerald, 2019). COX-2-derived $\mathrm{PGE}_{2}$ was found to play an important role in oocyte maturation and fertilization by affecting the activity of the cumulus cells surrounding the oocyte (McAdam et al., 1999). Defective embryo implantation and decidualisation were also observed in COX-2-deficient mice uteri, indicating the fundamental role of PGs in normal uterus physiology (Lim et al., 1999; McAdam et al., 1999).

The importance of eicosanoids in parturition has been subjected to detailed investigations using knockdown animal models. For example, parturition defects were observed in rodents deficient of COX enzymes and $\mathrm{PGF}_{2 \alpha}$ receptor. Mice with targeted disruption of COX-1 gene had delayed parturition, resulting in neonatal death (Gross et al., 1998; Yu et al., 2005). $\mathrm{PGF}_{2 \alpha}$ receptor-deficient mice, generated by gene knockdown, did not show the normal decline of serum levels of progesterone associated with parturition and consequentially were unable to deliver normal fetuses at term (Sugimoto et al., 1997). Additionally, many clinical observations have accumulated evidences that demonstrate the likely regulatory function of PGs on myometrial contractility and cervical softening. For instance, administration of PGs biosynthesis inhibitors such as aspirin or specific COX-2 (also known as prostaglandin endoperoxide synthase-2; PGHS or PTGS-2) inhibitors extend gestational length, however, does not prevent parturition (Lewis and Schulman, 1973; Collins and Turner, 1975; Khanprakob et al., 2012; Illanes et al., 2014; Triggs et al., 2020). Likewise, administration of $\mathrm{PGE}_{2}$ and $\mathrm{PGF}_{2 \alpha}$ at any stage of gestation leads to increasing uterine contractile activity and cervical ripening (Embrey, 1971). Consequently, PGs are used clinically as a treatment to induce labor (Thomas et al., 2014). Furthermore, production of $\mathrm{PGE}_{2}$ and $\mathrm{PGF}_{2 \alpha}$ increases during late stages of gestation and were found to be associated with the onset of parturition (Romero et al., 1994a, 1996; Slater et al., 1999). This confirms the notion that increased intrauterine PG biosynthesis is a cause rather than a result of the parturition process.

\section{Term Labor and Intrauterine Prostaglandin Concentrations}

During pregnancy, there are two main groups of regulatory factors that control the contractile activity of the uterus, uterotropins and uterotonins. Uterotropins and relaxatory uterotonins, such as progesterone and PGI, respectively, enhance myometrial relaxation and modulate uterine function and growth (Ilicic et al., 2020). Contrarily, stimulatory uterotonins, such as PGs, can induce contractions of the uteri. Before the parturition process starts, a relaxation state of the myometrium with minimum sensitivity to stimulatory uterotonins, such as PGs, is controlled by progesterone (Mesiano, 2004; Ilicic et al., 2020). Progesterone is a key player in the establishment and maintenance of pregnancy and its role and regulation have been extensively studied in human and experimental models (Arck et al., 2007; Forde et al., 2009; Solano and Arck, 2020). Progesterone withdrawal usually indicates the initiation of the parturition process with changes in the contractile activity of the myometrium. Human parturition is also associated with progesterone receptor subtypes changes (Merlino et al., 2007; Patel et al., 2015).

Although the required enzymes and receptors necessary for the synthesis and action of PGs are present in human myometrial tissue (Astle et al., 2007; Arulkumaran et al., 2012), their concentrations in the uterus may vary during various stages of gestation. During pregnancy, both maternal and fetal tissues produce $\mathrm{PGE}_{2}$ and $\mathrm{PGF}_{2} \alpha$. The increased intrauterine prostaglandin concentrations are key players in initiating and progressing labor and this occurs before the onset of labor (Romero et al., 1994a, 1996).

During the initial stage of the parturition process, myometrial cellular expression of PG-related genes is significantly increased: these genes include PG biosynthetic enzymes and PG receptors (Challis et al., 2002). The changed expression of these genes in turn increases the uterine tissue sensitivity to the elevated production of $\mathrm{PGE}_{2}$ and $\mathrm{PGF}_{2 \alpha}$. This leads to greater contractile activity that leads to expulsion of the fetus and sequentially expulsion of the placenta (Challis, 2013).

The balance between PG biosynthesis and metabolizing activities in the fetal membranes plays an important role in the parturition process. Intrauterine PG biosynthesis via PGHS occurs in the amnion and to a lesser extent in the chorion, decidua and myometrium. Conversely, prostaglandin dehydrogenase (PGDH) enzyme, which controls the conversion of $\mathrm{PGE}_{2}$ and $\mathrm{PGF}_{2 \alpha}$ to their inactive forms, is predominantly expressed in the chorion before the onset of labor. This leads to the prevention of active amnion-derived PGs reaching the myometrium due to the abundant presence of PGDH in the chorion which lies between the amnion and maternal tissues (Mesiano, 2019).

During parturition, expression of PGHS increases in the chorion, decidua and myometrium. In the meantime, expression of PGDH decreases in the chorion. This leads to greater abundance of active PGs in the chorion and permitting more $\mathrm{PGE}_{2}$ and $\mathrm{PGF}_{2 \alpha}$ to reach and induce their contractile action on the myometrium leading to progression of labor.

Of note, progesterone stimulates PGDH and has been reported to inhibit PTGS2 in the relaxed state of the myometrium before the onset of the parturition process (Pomini et al., 2000; Patel et al., 2003). Conversely, placental cortisol and corticotrophin-releasing hormone $(\mathrm{CRH})$ can stimulate PTGS2 and inhibit PGDH, causing increased access of active PGs to the myometrium (Olson and Ammann, 2007).

PG receptors also play a crucial role in regulating $P G$ action during human parturition. Receptors for $\mathrm{PGI}_{2}, \mathrm{PGE}_{2}$, $\mathrm{PGF}_{2 \alpha}$ and thromboxane are expressed in the myometrium during pregnancy (Grigsby et al., 2006). $\mathrm{PGF}_{2 \alpha}$ receptor (FP) and thromboxane receptor (TP) enhance contractions by increasing the intracellular calcium (Ricciotti and FitzGerald, 2011). Both $\mathrm{PGI}_{2}$ and $\mathrm{PGE}_{2}$ have contrary contractile actions on the myometrium. $\mathrm{PGI}_{2}$ receptor (IP) mediates elevated levels of cAMP which in turn leads to relaxation. However, $\mathrm{PGI}_{2}$ has been found to play a role in increasing expression of contraction-associated proteins, such as PTGS2 and PG receptors. Interestingly, $\mathrm{PGE}_{2}$ has four different receptors (EP1-4) with different physiologic actions. While contractile 
activity increases when $\mathrm{PGE}_{2}$ interacts with EP1 and EP3, relaxation of the tissue can be mediated by $\mathrm{PGE}_{2}$ interaction with EP2 and EP4 (Kotani et al., 1995). Therefore, PGE 2 can cause myometrial contraction or relaxation dependent upon the expression of receptor in different stages of pregnancy and during parturition.

A large literature illustrates the involvement of PGs in the five physiological events of human parturition: fetal membrane rupture via stimulating matrix mettaloproteinase activity and cell apoptosis (McLaren et al., 2000; Keelan et al., 2001), cervical ripening and dilation (Fletcher et al., 1993; Keirse, 1993; Steetskamp et al., 2020), myometrial contractility (Olson and Ammann, 2007), placental separation and uterine involution (Leung et al., 1987). This indicates the importance of further understanding the role of eicosanoids play in prognosis of pregnancy outcomes and their potential role as a diagnostic biomarker for fetus abnormalities and pregnancy complications, such as preeclampsia, gestational diabetes and preterm labor (Dalle Vedove et al., 2016; Hong et al., 2016; Aung et al., 2019; Welch et al., 2020).

\section{Preterm Labor and Inflammatory Mechanisms}

Labor that occurs before 37 completed weeks of gestation is considered as preterm, and preterm birth is the leading cause of perinatal mortality and morbidity (Goldenberg et al., 2008). The reasons behind the early onset of labor are not clearly identified (Green et al., 2005). Maternal infection is strongly correlated with preterm labor, such as intrauterine infection (Doi, 2020; Romero et al., 1994b). However, preterm delivery is associated with many other risk factors such as multifetal pregnancy, maternal obesity, maternal age, maternal nutrition and socioeconomic status (Johansson et al., 2014; Joseph et al., 2014; Koullali et al., 2016).

Inflammatory mechanisms are significantly involved in term and preterm labor (Christiaens et al., 2008; Peiris et al., 2019, 2020). Many studies focused on identifying labor-associated inflammatory genes profile, such as genes regulating cytokines, chemokines and related factors [reviewed in (Keelan et al., 2003)] which found to be upregulated in term deliveries and more apparently in preterm deliveries (Marvin et al., 2002; Mitchell, 2016). In term labor, infiltration of inflammatory cells increases in the cervix, myometrium, chorioamniotic membranes, and amniotic cavity. This is also found to be associated with increased expression and production of proinflammatory cytokines, such as interleukin (IL)-1 $\beta$, IL-6 and tumor necrosis factor- $\alpha(\mathrm{TNF} \alpha)$, and chemokines, such as IL-8 and growth-related oncogene- $\alpha$ (GRO $\alpha)$ (Keelan et al., 2003; Romero et al., 2006). Cytokine regulation of intrauterine prostaglandin production was found to be at the biosynthesis level and the catabolic inactivation level. For instance, IL-1 $\beta$ and TNF- $\alpha$ enhance upregulated expression of PGHS leading to increased biosynthesis of prostaglandins by gestational tissues (Hansen et al., 1999; Rauk and Chiao, 2000). Similarly, proinflammatory cytokines, IL-1 $\beta$ and $\mathrm{TNF} \alpha$ may inhibit PGDH leading to decreased degradation of prostaglandins (Brown et al., 1998; Mitchell et al., 2000). The role of pro-inflammatory cytokines in regulating prostaglandin production is further evidence of the importance of inflammatory mechanisms in mediating parturition (Gross et al., 2000; Peiris et al., 2019, 2020).

Similarly, infection and non-infection-induced inflammation have been found to be associated with preterm labor (Yoon et al., 2001; Romero et al., 2014, 2015). There are many experimental and clinical evidences in support of the involvement of inflammation in preterm labor. For example, pregnant animal models with intrauterine infection or with exposure to microbial products can lead to preterm delivery [reviewed in (Elovitz and Mrinalini, 2004)]. Extrauterine and sub-clinical intrauterine maternal infections have been associated with premature parturition (Gomez et al., 1995; Romero et al., 2006). The production of pro-inflammatory cytokines such as IL-1 $\beta$, IL8 , and IL-6 are usually increased in the amnion, decidua and myometrium in pregnancies with infection (Goldenberg et al., 2000). This confirms the notion that parturition is a consequence of failure of the maternal immune system to regulate inflammatory mechanisms (Romero et al., 2006).

\section{Eicosanoid Distribution and Measurement}

Due to the importance of eicosanoids in pregnancy and parturition, the accurate and specific measurement of eicosanoids is critical to our ability to enhance diagnostic and therapeutic strategies for preterm labor. However, the misidentification of PGs has been problematic with traditional methodologies such as immunoassays (Glass et al., 2005). Previously we reviewed the molecular resemblance between eicosanoids and associated compounds that may interfere and affect the specificity of immunoassays (Glass et al., 2005; Peiris et al., 2017). Thus, the gold standard of mass spectrometry that allows full identification of PGs is vital to any meaningful approach to this problem (Peiris et al., 2020).

Prostaglandins are produced by all tissues in the body. Hence measurements of circulating concentrations reflect overall changes in production and cannot be directly linked to a specific tissue or organ source. Moreover, due to rapid clearance of circulating eicosanoids by lungs and kidneys (Golub et al., 1975; Dunn and Hood, 1977; Peiris et al., 2017), we can only assess circulating metabolites of eicosanoids not the original compounds. Therefore, there is a strong argument for evaluating the utility of exosomes (which have a content that reflects the tissue/cellular source) as a stable biomarker for measuring and identifying eicosanoids from specific organs such as the uterus.

\section{EXOSOMES}

\section{Exosome Morphology}

Exosomes are a subtype of membrane bound extracellular vesicles (EVs); they are 30-120 $\mathrm{nm}$ in diameter and have a cup-shaped structure and a lipid bilayer which is similar in orientation of transmembrane constituents to that of the parental cells membrane (Record, 2014; Barile and Vassalli, 2017; Shao et al., 2018). Exosomes contain a diverse array of biologically active molecules such as proteins, lipids, RNA (mRNA, microRNA and noncoding RNA), DNA, protein mediators and eicosanoids (Pillay et al., 2017; Saez et al., 2018). Exosomal contents comprise 
specific proteins, lipids or genetic materials reflecting the source cell's physiological state, and can therefore serve as representative biomarkers (Menon et al., 2017).

\section{Exosome Biogenesis}

The biogenesis of exosomes involves the inward budding of the peripheral membrane and invagination of the late endosomes also known as Multivesicular Bodies (MVB) (Record, 2014); followed by the formation of intraluminal vesicles (ILVs) inside of the MVB's (Zhang et al., 2019). During the invagination process, proteins are incorporated into the membrane, leaving the cytosolic components to be engulfed into the ILVs (Zhang et al., 2019). MVBs are then fused with the plasma membrane of the cell releasing ILVs out into the extracellular space; once released ILVs are then referred to as exosomes (Kowal et al., 2014; Zhang et al., 2019; Figure 2). Exosomes biogenesis also requires; Endosomal Sorting Complexes for Transport (ESCRT) 0-III. This complex contains families of vacuolar sorting proteins, other associated proteins (e.g., Alix and tetraspanin) and lipids which also participate in protein sorting and ILV formation during biogenesis (Kowal et al., 2014). The selective packaging of molecules into exosomes occurs within the originating cell (Pillay et al., 2017); constituents within exosomes come from an array of cellular components such as the Golgi apparatus, endoplasmic reticulum, plasma membrane, nucleus and cytosol (Record, 2014), meaning that exosomes can represent many different parts of the cell. The few known selective mechanisms that regulate cargo sorting into exosomes have recently reviewed (Anand et al., 2019).

\section{Exosome Secretion and Function}

The exocytosis of exosomes is an active secretory process (Record, 2014). MVBs move along microtubules toward the cell's periphery fusing with the plasma membrane and causing the release of exosomes into the extracellular space (Zhang et al., 2019). Connection of the MVB and the microtubule organization center (MTOC) allows the sectorisation of exosome release, restricting the release of exosomes to non-random areas of the cell membrane (Record, 2014). Exosome release is also dependent on the cells and conditions of their surrounding environment (Kowal et al., 2014; Barile and Vassalli, 2017).

Once exosomes are released, they become involved in communication between cells through cargo delivery to the recipient cells. There are three main types signaling modes; autocrine affects the releasing cell, paracrine affects adjacent cells and endocrine is delivered to distal target cells via the circulation.

Exosomes are a device for both transportation and signaling; through their load of bioactive molecules, they have the innate ability to signal from inside a target cell; both from the periphery and intracellular compartments (Record, 2014).

The function of exosomes is to exchange information through the delivery of cargo to distal and adjacent target cells. In doing so, the interaction of target cells with exosomes results in reprogramming of their phenotype and regulation of their function; functions such as migration, proliferation, angiogenesis, translational activity, metabolism, and apoptosis (Ehrlich et al., 2016; Saez et al., 2018). This reprogramming and regulation consequently alters cellular physiology, and in some cases contributing to different pathological states (Pillay et al., 2017).

\section{Exosomes in Pregnancy Synthesis and Interactions With Surrounding Environment}

Exosomes have been identified in the maternal circulation as early as 6 weeks into gestation (Salomon et al., 2014). As gestational age increases, there is an increase in circulating maternal exosome concentration (Pillay et al., 2017); with the increased exosome burden likely related to placental mass and derived primarily from placental mesenchymal stem cells.

First-trimester trophoblast cells act as environmental sensors, and these cells can respond to the changing environment via the synthesis and release of exosomes (Mitchell et al., 2015). For example, an increase of exosome numbers is observed when the in vitro environment has a low oxygen tension and is high in $\mathrm{D}$ glucose concentration; these two factors synergistically interact to regulate the bioactivity and release of exosomes originating from first-trimester trophoblast cells.

The effect of environmental factors on the release of exosomes into the maternal circulation via endocrinal communication is dependent on the integrity and stability of exosomes (Ehrlich et al., 2016). For example, increased release of exosomes from trophoblastic cells is seen as a response to challenging environmental conditions (e.g., elevated glucose concentrations and low oxygen tension) which might disrupt the balance of cytokines (Truong et al., 2017). Cytokines being a necessity for healthy implantation, placentation and successful pregnancy outcome (Mitchell et al., 2015).

\section{Exchange, Mediatory Roles, and Other Functions}

A function of placenta-derived exosomes is to be a mediator in the progression of pregnancy and cell fate. Exosomes are used in cell-to-cell communication between the placenta and maternal organs. This communication has many functions, one of which is the preparatory function of remote tissues for metabolic and placental changes during gestation (Greening et al., 2016; Jin and Menon, 2018).

Basic functions of exosomes in normal uncomplicated pregnancies are promotion of implantation and communication between endometrium and embryo (Jin and Menon, 2018). In vitro studies have also revealed the role of exosomes in differential endothelial cell migration and vascular tube formation. Additionally, exosomes have a pivotal immunoregulatory role via the initiation of activated maternal lymphocytes' local deletion and induction of maternal t-cell apoptosis, which prevents the degradation of invading trophoblastic cells (Greening et al., 2016; Pillay et al., 2017). Placenta-derived exosomes are also found to play a role in viral infection during pregnancy, where trophoblast cells can transfer the necessary capacity of resistance against viral infection to other nonplacental cells via exosomes (Mouillet et al., 2014).

Exosomes regulate all these functions through the transference of their content into target cells. This regulation of activity 


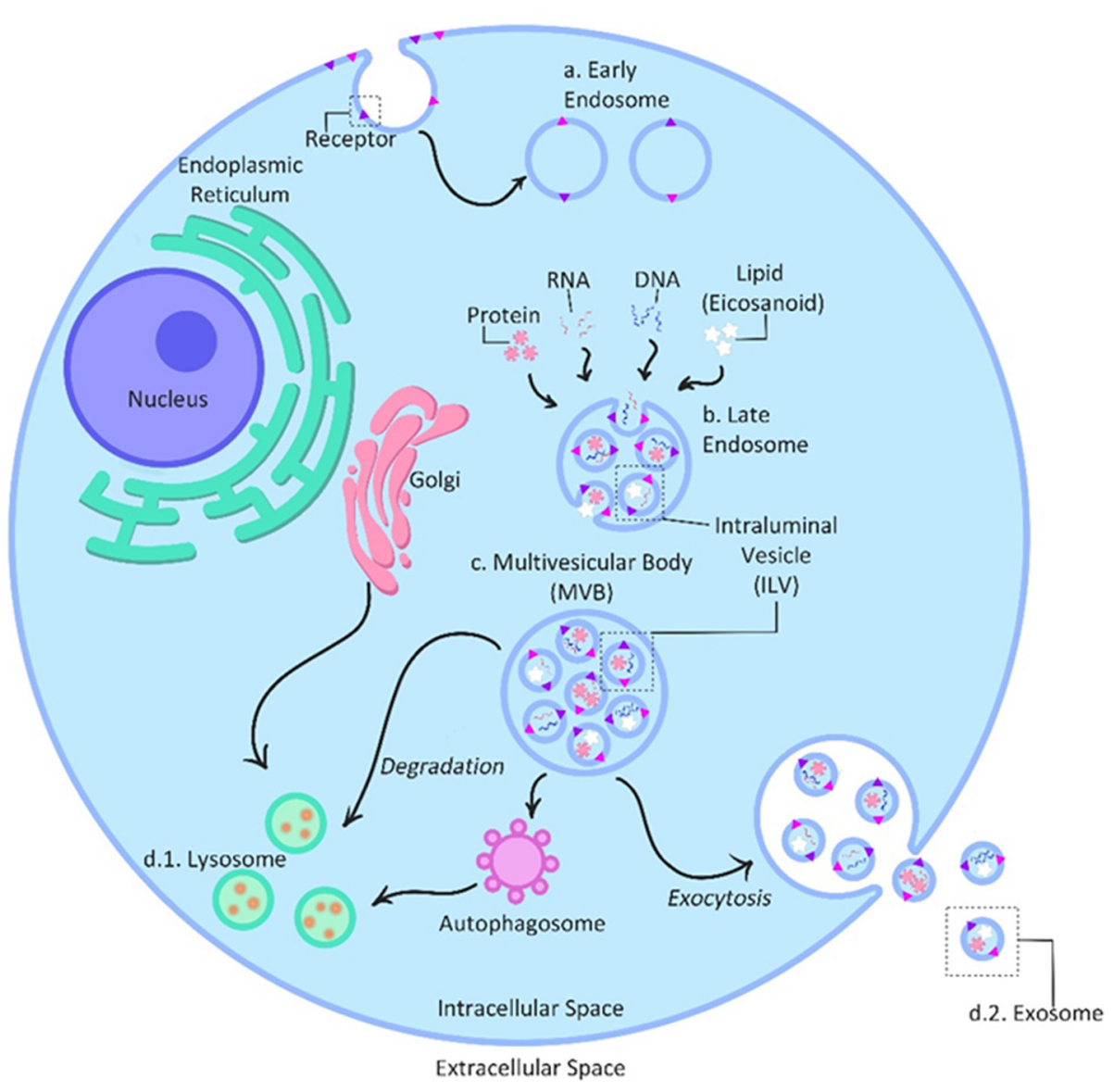

FIGURE 2 | Exosome biogenesis and secretion. The biogenesis of exosomes is initiated with the inward budding of the peripheral membrane into early endosomes (a). Selective exosome packaging with molecules such as protein, RNA and DNA and lipids occurs within the originating cell and cellular compartments such as the Golgi apparatus, endoplasmic reticulum, plasma membrane, nucleus and cytosol. Invagination of the early endosomes into late endosomes (b) allows these diverse molecules to be taken up and individually packaged inside intraluminal vesicles (ILVs), turning the endosomes into multivesicular bodies (MVBs) (c). During the invagination process, proteins are incorporated into the membrane, leaving the cytosolic components to be engulfed into the ILVs. Finally, MVBs either release ILVs intracellularly to be absorbed by lysosomes/autophagosomes (d.1) for degradation or fuse with the plasma membrane to secrete ILVs out into the extracellular space as exosomes (d.2). [After (Kowal et al., 2014)].

can occur with either proximal or distal target cells via different interactions; this includes the modification of the extracellular milieu of the target cell, activation of cell membrane receptors, endocytosis by target cells in which the cell contents are released intracellularly and translational activity (e.g., angiogenesis, proliferation, metabolism and apoptosis). Exosomes can then modify the phenotype of these cells through maternal circulation.

The internalization of exosomes is also found to induce the release of pro-inflammatory cytokines (Greening et al., 2016). Exosomes released due to abnormal environmental factors lead to dysfunction of feto-placental endothelium and other various types of endothelial exosomes (Saez et al., 2018).

The involvement of exosomes in the transcellular metabolism of eicosanoids (and enzymes involved in substrate release for eicosanoids) has been described specifically and in terms of lipid mediators in a series of studies. In these studies exosomes from cells contained the full range of phospholipases and many free fatty acids (Subra et al., 2010; Record et al., 2014). The internalization of exosomes was described and the subsequent utilization of exosome cargo in cell metabolism (Subra et al., 2010) as well as involvement of this intercellular trafficking in pathophysiologies (Record et al., 2014). We have recently reviewed this in detail in an invited publication (Peiris et al., 2017).

Various studies have demonstrated the pivotal role of exosomes during human pregnancy and parturition (Sarker et al., 2014; Mitchell et al., 2015; Menon et al., 2017; Jin and Menon, 2018; Sheller-Miller and Menon, 2020). More interestingly, the potential role of exosomes in diagnosis/prognosis of pregnancy complications has gained a lot of attention in the scientific field in the last two decades. For example, preterm labor was one of the main topic that is under investigation (Cantonwine et al., 2016; Menon and Richardson, 2017; von Linsingen et al., 2017). Likewise, studies on gestational diabetes 
(Powe, 2017; Liu et al., 2018; Saez et al., 2018) and preeclampsia (Pillay et al., 2016; Nielsen et al., 2017; Navajas et al., 2019) showed differential exosomal contents compared to that in uncomplicated pregnancies.

\section{FINAL REMARKS}

The intercellular communication mediated by exosomes has opened new era of research to study biological processes in healthy and pathophysiological conditions. From a clinical perspective, exosomes are mainly used in two applications: as biomarker detection and biologically active carriers. Exosomes are potential candidates as biomarkers detection tool circulating in blood. Enrichment of specific markers can be improved by exosome isolation and cargo identification (Record et al., 2018). Exosomes may transport proteins, lipids and nucleic acids that can be used as diagnostic or prognostic markers for specific clinical conditions. In this respect, several studies identified potential exosomal markers for early detection, diagnosis, and monitoring of cancer patients (Melo et al., 2015; Jalalian et al., 2019; Makler and Asghar, 2020). Similarly, exosomal contents are now gaining much attention in the field of pregnancy complications and fetal abnormalities (Yang et al., 2020). On the other hand, exosomes are now identified as potential platform for enhanced delivery of specific cargo in vivo, which can be biological compounds or therapeutic agents. The methods of loading exosomes with specific cargos of interest have been recently reviewed (Li et al., 2018; Donoso-Quezada et al., 2020; Mitchell et al., 2020). Exosomes have also inspired researchers to use cell-membrane-cloaked nanoparticles, also called synthetic exosome-mimics, as drug delivery platforms (Hu et al., 2011, 2015; Cao et al., 2016). These different applications of exosomes can provide hope to many patients including women with complicated pregnancies.

The relationship and importance of eicosanoids in pregnancy, labor and parturition are well established and have been an area of research for many decades. However, the limitations of immunoassays in the accurate measurement of specific eicosanoids have hampered research. The development of sensitive and specific mass spectrometry-based method to

\section{REFERENCES}

Alexandre, B., Lemaire, A., Desvaux, P., and Amar, E. (2007). ORIGINAL RESEARCH-ED PHARMACOTHERAPY: intracavernous injections of prostaglandin E1 for erectile dysfunction: patient satisfaction and quality of sex life on long-term treatment. J. Sex. Med. 4, 426-431. doi: 10.1111/j.1743-6109.2006.00260.x

Anand, S., Samuel, M., Kumar, S., and Mathivanan, S. (2019). Ticket to a bubble ride: cargo sorting into exosomes and extracellular vesicles. Biochim. Biophys. Acta Proteins Proteom. 1867:140203. doi: 10.1016/j.bbapap.2019.02.005

Arck, P., Hansen, P. J., Mulac Jericevic, B., Piccinni, M.-P., and Szekeres-Bartho, J. (2007). Progesterone during pregnancy: endocrine-immune cross talk in mammalian species and the role of stress. Am. J. Reprod. Immunol. 58, 268-279. doi: 10.1111/j.1600-0897.2007.00512.x

Arulkumaran, S., Kandola, M. K., Hoffman, B., Hanyaloglu, A. C., Johnson, M. R., and Bennett, P. R. (2012). The roles of prostaglandin EP 1 and 3 receptors in the control of human myometrial contractility. J. Clin. Endocrinol. Metab. 97, 489-498. doi: 10.1210/jc.2011-1991 measure individual eicosanoids (e.g., prostaglandins and prostamides) via the monitoring of characteristic mass fragment pairs for each molecule at their distinct retention times has overcome these technical limitations and for the first time allowed accurate measurement of specific eicosanoids (Mitchell et al., 2016). A small but growing number of clinical studies have adopted mass spectrometric evaluations of these compounds, which has led to important new findings in the areas of labor and uterine infection (Maddipati et al., 2014, 2016; Peiris et al., 2020). The identification of the building blocks and enzymes needed for the synthesis of eicosanoids within exosomes is doubly exciting (Subra et al., 2010; Record et al., 2014). Firstly, the evaluation and quantitation of the cargo may provide a real-time snapshot of the cells' state. Secondly, exploration of the exosomes' abilities as vesicles of intercellular communication (i.e., to transport and deliver messages between cells) may further our understanding of the parturition process and provide opportunities to reconsider the mechanisms of pregnancy and parturition.

We postulate that together, understanding and quantitating eicosanoid biosynthesis, metabolism and actions in combination with exosome biology will enable the discovery of diagnostic and prognostic biomarkers for many pregnancy complications including preterm labor.

\section{AUTHOR CONTRIBUTIONS}

MM conceived the idea. EM and IMG prepared figures. EM, $\mathrm{HP}, \mathrm{OH}, \mathrm{IMG}$, and $\mathrm{MM}$ contributed to manuscript writing. All authors contributed to the article and approved the submitted version.

\section{ACKNOWLEDGMENTS}

We thank our many colleagues who have assisted in the development of these studies over the years. We are also grateful to Queensland University of Technology for support and infrastructure. EM salary is supported by the Australian Research Council (Grant No: ARC LP160101854).

Astle, S., Newton, R., Thornton, S., Vatish, M., and Slater, D. M. (2007). Expression and regulation of prostaglandin $\mathrm{E}$ synthase isoforms in human myometrium with labour. Mol. Hum. Reprod. 13, 69-75. doi: 10.1093/molehr/gal093

Aung, M. T., Yu, Y., Ferguson, K. K., Cantonwine, D. E., Zeng, L., McElrath, T. F., et al. (2019). Prediction and associations of preterm birth and its subtypes with eicosanoid enzymatic pathways and inflammatory markers. Sci. Rep. 9, 1-17.

Bäck, M., Dahlén, S.-E., Drazen, J. M., Evans, J. F., Serhan, C. N., Shimizu, T., et al. (2011). International union of basic and clinical pharmacology. LXXXIV: leukotriene receptor nomenclature, distribution, and pathophysiological functions. Pharmacol. Rev. 63, 539-584.

Barile, L., and Vassalli, G. (2017). Exosomes: therapy delivery tools and biomarkers of diseases. Pharmacol. Therap. 174, 63-78. doi: 10.1016/j.pharmthera.2017.02. 020

Bennegård, B., Hahlin, M., Wennberg, E., and Norém, H. (1991). Local luteolytic effect of prostaglandin F2 $\alpha$ in the human corpus luteum. Fertil. Steril. 56, 1070-1076.

Brown, N. L., Alvi, S. A., Elder, M. G., Bennett, P. R., and Sullivan, M. H. (1998). Regulation of prostaglandin production in intact fetal membranes by 
interleukin-1 and its receptor antagonist. J. Endocrinol. 159, 519-526. doi: 10. 1677/joe.0.1590519

Burke, J. E., and Dennis, E. A. (2009). Phospholipase A2 structure/function, mechanism, and signaling. J. Lipid Res. 50, S237-S242.

Cantonwine, D. E., Zhang, Z., Rosenblatt, K., Goudy, K. S., Doss, R. C., Ezrin, A. M., et al. (2016). Evaluation of proteomic biomarkers associated with circulating microparticles as an effective means to stratify the risk of spontaneous preterm birth. Am. J. Obstetr. Gynecol. 214:631.

Cao, H., Dan, Z., He, X., Zhang, Z., Yu, H., Yin, Q., et al. (2016). Liposomes coated with isolated macrophage membrane can target lung metastasis of breast cancer. ACS Nano 10, 7738-7748.

Challis, J. (2013). Prostaglandins and Parturition. 51st Congress of the German Society for Gynecology and Obstetrics: Gynecology and Gynecological Oncology, Obstetrics, Perinatology and Prenatal Diagnostics, Gynecological Endocrinology and Reproductive Medicine. Dresden: Springer-Verlag.

Challis, J. R. G., Bloomfield, F. H., Bocking, A. D., Casciani, V., Chisaka, H., Connor, K., et al. (2005). Fetal signals and parturition. J. Obstetr. Gynaecol. Res. 31, 492-499. doi: 10.1111/j.1447-0756.2005.00342.x

Challis, J. R. G., Sloboda, D. M., Alfaidy, N., Lye, S. J., Gibb, W., Patel, F. A., et al. (2002). Prostaglandins and mechanisms of preterm birth [Review]. Reproduction 124, 1-17. doi: 10.1530/rep.0.1240001

Christiaens, I., Zaragoza, D. B., Guilbert, L., Robertson, S. A., Mitchell, B. F., and Olson, D. M. (2008). Inflammatory processes in preterm and term parturition. J. Reprod. Immunol. 79, 50-57.

Collins, E., and Turner, G. (1975). Maternal effects of regular salicylate ingestion in pregnancy. Lancet 2, 335-338. doi: 10.1016/s0140-6736(75)92777-4

Dalle Vedove, F., Fava, C., Jiang, H., Zanconato, G., Quilley, J., Brunelli, M., et al. (2016). Increased epoxyeicosatrienoic acids and reduced soluble epoxide hydrolase expression in the preeclamptic placenta. J. Hypertension 34:1364.

Doi, K. (2020). "Multiple mechanisms of preterm labour other than intrauterine infection," in Preterm Labour and Delivery, ed. H. Sameshima (Singapore: Springer), 89-94.

Donoso-Quezada, J., Ayala-Mar, S., and González-Valdez, J. (2020). Stateof-the-art exosome loading and functionalization techniques for enhanced therapeutics: a review. Crit. Rev. Biotechnol. 40, 804-820.

Dunn, M. J., and Hood, V. L. (1977). Prostaglandins and the kidney. Am. J. Physiol. Renal Physiol. 233, F169-F184.

Ehrlich, S., Lambers, D., Baccarelli, A., Khoury, J., Macaluso, M., and Ho, S. M. (2016). Endocrine disruptors: a potential risk factor for gestational diabetes mellitus. Am. J. Perinatol. 33, 1313-1318. doi: 10.1055/s-0036-1586500

Elovitz, M. A., and Mrinalini, C. (2004). Animal models of preterm birth. Trends Endocrinol. Metab. 15, 479-487. doi: 10.1016/j.tem.2004.10.009

Embrey, M. (1971). PGE compounds for induction of labour and abortion. Ann. N. Y. Acad. Sci. 180, 518-523. doi: 10.1111/j.1749-6632.1971.tb53219.x

Esser-von Bieren, J. (2017). Immune-regulation and-functions of eicosanoid lipid mediators. Biol. Chem. 398, 1177-1191.

Fitzpatrick, F., and Soberman, R. (2001). Regulated formation of eicosanoids. J. Clin. Invest. 107, 1347-1351.

Fletcher, H., Mitchell, S., Simeon, D., Frederick, J., and Brown, D. (1993). Intravaginal misoprostol as a cervical ripening agent. Br. J. Obstet. Gynaecol. $100,641-644$

Forde, N., Carter, F., Fair, T., Crowe, M. A., Evans, A. C. O., Spencer, T. E., et al. (2009). Progesterone-regulated changes in endometrial gene expression contribute to advanced conceptus development in cattle1. Biol. Reprod. 81, 784-794. doi: 10.1095/biolreprod.108.074336

Funk, C. D. (2001). Prostaglandins and leukotrienes: advances in eicosanoid biology. Science 294, 1871-1875.

Glass, M., Hong, J., Sato, T. A., and Mitchell, M. D. (2005). Misidentification of prostamides as prostaglandins. J. Lipid Res. 46, 1364-1368.

Goldenberg, R. L., Culhane, J. F., Iams, J. D., and Romero, R. (2008). Epidemiology and causes of preterm birth. Lancet 371, 75-84.

Goldenberg, R. L., Hauth, J. C., and Andrews, W. W. (2000). Intrauterine infection and preterm delivery. N. Engl. J. Med. 342, 1500-1507. doi: 10.1056/ nejm200005183422007

Golub, M., Zia, P., Matsuno, M., and Horton, R. (1975). Metabolism of prostaglandins A1 and E1 in man. J. Clin. Invest. 56, 1404-1410.

Gomez, R., Ghezzi, F., Romero, R., Muñoz, H., Tolosa, J. E., and Rojas, I. (1995). Premature labour and intra-amniotic infection: clinical aspects and role of the cytokines in diagnosis and pathophysiology. Clin. Perinatol. 22, 281-342. doi: 10.1016/S0095-5108(18)30286-0

Green, N. S., Damus, K., Simpson, J. L., Iams, J., Reece, E. A., Hobel, C. J., et al. (2005). Research agenda for preterm birth: recommendations from the March of Dimes. Am. J. Obstet. Gynecol. 193(Pt 1), 626-635. doi: 10.1016/j.ajog.2005. 02.106

Greening, D. W., Nguyen, H. P., Elgass, K., Simpson, R. J., and Salamonsen, L. A. (2016). Human endometrial exosomes contain hormone-specific cargo modulating trophoblast adhesive capacity: insights into endometrial-embryo interactions. Biol. Reprod. 94:38.

Grigsby, P. L., Sooranna, S. R., Adu-Amankwa, B., Pitzer, B., Brockman, D. E., Johnson, M. R., et al. (2006). Regional expression of prostaglandin E2 and F2alpha receptors in human myometrium, amnion, and choriodecidua with advancing gestation and labour. Biol. Reprod. 75, 297-305. doi: 10.1095/ biolreprod.106.051987

Gross, G., Imamura, T., Vogt, S. K., Wozniak, D. F., Nelson, D. M., Sadovsky, Y., et al. (2000). Inhibition of cyclooxygenase-2 prevents inflammation-mediated preterm labour in the mouse. Am. J. Physiol. Regul. Integr. Comp. Physiol. 278, R1415-R1423. doi: 10.1152/ajpregu.2000.278.6.R1415

Gross, G. A., Imamura, T., Luedke, C., Vogt, S. K., Olson, L. M., Nelson, D. M., et al. (1998). Opposing actions of prostaglandins and oxytocin determine the onset of murine labour. Proc. Natl. Acad. Sci. U.S.A. 95, 11875-11879. doi: 10.1073/pnas.95.20.11875

Hanna, V. S., and Hafez, E. A. A. (2018). Synopsis of arachidonic acid metabolism: a review. J. Adv. Res. 11, 23-32. doi: 10.1016/j.jare.2018.03.005

Hansen, W., Keelan, J., Skinner, S., and Mitchell, M. (1999). Key enzymes of prostaglandin biosynthesis and metabolism. Coordinate regulation of expression by cytokines in gestational tissues: a review. Prostaglandins Other Lipid Mediat. 57, 243-257.

Herschman, H. R. (1996). Prostaglandin synthase 2. Biochim. Biophys. Acta 1299, 125-140. doi: 10.1016/0005-2760(95)00194-8

Hong, J.-S., Romero, R., Lee, D.-C., Than, N. G., Yeo, L., Chaemsaithong, P., et al. (2016). Umbilical cord prostaglandins in term and preterm parturition. J. Mater. Fetal Neonatal Med. 29, 523-531.

Hu, C.-M. J., Fang, R. H., Wang, K.-C., Luk, B. T., Thamphiwatana, S., Dehaini, D., et al. (2015). Nanoparticle biointerfacing by platelet membrane cloaking. Nature $526,118-121$.

Hu, C.-M. J., Zhang, L., Aryal, S., Cheung, C., Fang, R. H., and Zhang, L. (2011). Erythrocyte membrane-camouflaged polymeric nanoparticles as a biomimetic delivery platform. Proc. Natl. Acad. Sci. U.S.A. 108, 10980-10985.

Ilicic, M., Zakar, T., and Paul, J. W. (2020). The regulation of uterine function during parturition: an update and recent advances. Reprod. Sci. 27, 3-28.

Illanes, S. E., Perez-Sepulveda, A., Rice, G. E., and Mitchell, M. D. (2014). Preterm labour: association between labour physiology, tocolysis and prevention. Expert Opin. Invest. Drugs 23, 759-771.

Jalalian, S. H., Ramezani, M., Jalalian, S. A., Abnous, K., and Taghdisi, S. M. (2019). Exosomes, new biomarkers in early cancer detection. Anal. Biochem. 571, 1-13.

Jin, J., and Menon, R. (2018). Placental exosomes: a proxy to understand pregnancy complications. Am. J. Reprod. Immunol. 79:e12788.

Johansson, S., Villamor, E., Altman, M., Bonamy, A. K., Granath, F., and Cnattingius, S. (2014). Maternal overweight and obesity in early pregnancy and risk of infant mortality: a population based cohort study in Sweden. BMJ 349:g6572. doi: 10.1136/bmj.g6572

Joseph, K. S., Fahey, J., Shankardass, K., Allen, V. M., O'Campo, P., Dodds, L., et al. (2014). Effects of socioeconomic position and clinical risk factors on spontaneous and iatrogenic preterm birth. BMC Pregnancy Childbirth 14:117. doi: 10.1186/1471-2393-14-117

Kano, M., Ohno-Shosaku, T., Hashimotodani, Y., Uchigashima, M., and Watanabe, M. (2009). Endocannabinoid-mediated control of synaptic transmission. Physiol. Rev. 89, 309-380.

Keelan, J. A., Blumenstein, M., Helliwell, R. J. A., Sato, T. A., Marvin, K. W., and Mitchell, M. D. (2003). Cytokines, prostaglandins and parturition-a review. Placenta 24, S33-S46. doi: 10.1053/plac.2002.0948

Keelan, J. A., Helliwell, R. J., Nijmeijer, B. E., Berry, E. B., Sato, T. A., Marvin, $\mathrm{K}$. W., et al. (2001). 15-deoxy- $\Delta 12$, 14-prostaglandin J2-induced apoptosis in amnion-like WISH cells. Prostaglandins Other Lipid Mediat. 66, 265-282.

Keirse, M. (1993). Prostaglandins in preinduction cervical ripening. Meta-analysis of worldwide clinical experience. J. Reprod. Med. 38, 89-100. 
Khanprakob, T., Laopaiboon, M., Lumbiganon, P., and Sangkomkamhang, U. S. (2012). Cyclo-oxygenase (COX) inhibitors for preventing preterm labour. Cochrane Database Syst. Rev. 10:CD007748.

Kim, N. D., and Luster, A. D. (2007). Regulation of immune cells by eicosanoid receptors. ScientificWorldJournal 7, 1307-1328.

Kotani, M., Tanaka, I., Ogawa, Y., Usui, T., Mori, K., Ichikawa, A., et al. (1995). Molecular cloning and expression of multiple isoforms of human prostaglandin E receptor EP3 subtype generated by alternative messenger RNA splicing: multiple second messenger systems and tissue-specific distributions. Mol. Pharmacol. 48, 869-879.

Koullali, B., Oudijk, M. A., Nijman, T. A., Mol, B. W., and Pajkrt, E. (2016). Risk assessment and management to prevent preterm birth. Semin. Fetal Neonatal Med. 21, 80-88. doi: 10.1016/j.siny.2016.01.005

Kowal, J., Tkach, M., and Théry, C. (2014). Biogenesis and secretion of exosomes. Curr. Opin. Cell Biol. 29, 116-125. doi: 10.1016/j.ceb.2014.05.004

Leung, A., Kwok, P., and Chang, A. (1987). Association between prostaglandin E2 and placental abruption. Br. J. Obstetr. Gynaecol. 94, 1001-1002.

Lewis, R. B., and Schulman, J. D. (1973). Influence of acetylsalicylic acid, an inhibitor of prostaglandin synthesis, on the duration of human gestation and labour. Lancet 2, 1159-1161. doi: 10.1016/s0140-6736(73)92934-6

Li, S.-P., Lin, Z.-X., Jiang, X.-Y., and Yu, X.-Y. (2018). Exosomal cargo-loading and synthetic exosome-mimics as potential therapeutic tools. Acta Pharmacol. Sin. 39, 542-551.

Lim, H., Gupta, R. A., Ma, W. G., Paria, B. C., Moller, D. E., Morrow, J. D., et al. (1999). Cyclo-oxygenase-2-derived prostacyclin mediates embryo implantation in the mouse via PPARdelta. Genes Dev. 13, 1561-1574. doi: 10.1101/gad.13.12. 1561

Liu, J., Wang, S., Wang, Q., Du, J., and Wang, B. (2018). Gestational diabetes mellitus is associated with changes in the concentration and bioactivity of placental exosomes in the maternal circulation across gestation. Eur. Rev. Med. Pharmacol. Sci. 22, 2036-2043.

Maddipati, K. R., Romero, R., Chaiworapongsa, T., Chaemsaithong, P., Zhou, S. L., $\mathrm{Xu}, \mathrm{Z}$., et al. (2016). Lipidomic analysis of patients with microbial invasion of the amniotic cavity reveals up-regulation of leukotriene B4. FASEB J. 30, 3296-3307.

Maddipati, K. R., Romero, R., Chaiworapongsa, T., Zhou, S. L., Xu, Z., Tarca, A. L., et al. (2014). Eicosanomic profiling reveals dominance of the epoxygenase pathway in human amniotic fluid at term in spontaneous labour. FASEB J. 28, 4835-4846.

Makler, A., and Asghar, W. (2020). Exosomal biomarkers for cancer diagnosis and patient monitoring. Expert Rev. Mol. Diagn. 20, 387-400.

Marvin, K., Keelan, J., Eykholt, R., Sato, T., and Mitchell, M. (2002). Use of cDNA arrays to generate differential expression profiles for inflammatory genes in human gestational membranes delivered at term and preterm. Mol. Hum. Reprod. 8, 399-408.

McAdam, B. F., Catella-Lawson, F., Mardini, I. A., Kapoor, S., Lawson, J. A., and FitzGerald, G. A. (1999). Systemic biosynthesis of prostacyclin by cyclooxygenase (COX)-2: the human pharmacology of a selective inhibitor of COX-2. Proc. Natl. Acad. Sci. U.S.A. 96, 272-277. doi: 10.1073/pnas.96.1.272

McLaren, J., Taylor, D., and Bell, S. (2000). Prostaglandin E2-dependent production of latent matrix metalloproteinase- 9 in cultures of human fetal membranes. Mol. Hum. Reprod. 6, 1033-1040.

Melo, S. A., Luecke, L. B., Kahlert, C., Fernandez, A. F., Gammon, S. T., Kaye, J., et al. (2015). Glypican-1 identifies cancer exosomes and detects early pancreatic cancer. Nature 523, 177-182.

Menon, R. (2016). Human fetal membranes at term: dead tissue or signalers of parturition? Placenta 44, 1-5. doi: 10.1016/j.placenta.2016.05.013

Menon, R., Mesiano, S., and Taylor, R. N. (2017). Programmed fetal membrane senescence and exosome-mediated signaling: a mechanism associated with timing of human parturition. Front. Endocrinol. 8:196. doi: 10.3389/fendo.2017. 00196

Menon, R., and Richardson, L. S. (2017). Preterm prelabour rupture of the membranes: a disease of the fetal membranes. Semin. Perinatol. 41, 409-419.

Merlino, A. A., Welsh, T. N., Tan, H., Yi, L. J., Cannon, V., Mercer, B. M., et al. (2007). Nuclear progesterone receptors in the human pregnancy myometrium: evidence that parturition involves functional progesterone withdrawal mediated by increased expression of progesterone receptor-A. J. Clin. Endocrinol. Metab. 92, 1927-1933.
Mesiano, S. (2004). Myometrial progesterone responsiveness and the control of human parturition. J. Soc. Gynecol. Invest. 11, 193-202.

Mesiano, S. (2019). "Chapter 11 - endocrinology of human pregnancy and fetal-placental neuroendocrine development," in Yen and Jaffe's Reproductive Endocrinology (Eighth Edition), eds J. F. Strauss and R. L. Barbieri (Amsterdam: Elsevier), 256-284e9. doi: 10.1016/B978-0-323-47912-7.00011-1

Miceli, F., Minici, F., Pardo, M. G., Navarra, P., Proto, C., Mancuso, S., et al. (2001). Endothelins enhance prostaglandin (PGE2 and PGF2 $\alpha$ ) biosynthesis and release by human luteal cells: evidence of a new paracrine/autocrine regulation of luteal function. J. Clin. Endocrinol. Metab. 86, 811-817. doi: 10. 1210/jcem.86.2.7236

Mitchell, C. M. (2016). Transcriptional and Epigenetic Regulation of Labour Associated Inflammatory Genes in the Amnion Faculty of Health. Callaghan, NSW: The University of Newcastle.

Mitchell, M. D., Crookenden, M. A., Vaswani, K., Roche, J. R., and Peiris, H. N. (2020). The frontiers of biomedical science and its application to animal science in addressing the major challenges facing Australasian dairy farming. Anim. Prod. Sci. 60, 1-9. doi: 10.1071/AN18579

Mitchell, M. D., Goodwin, V., Mesnage, S., and Keelan, J. A. (2000). Cytokineinduced coordinate expression of enzymes of prostaglandin biosynthesis and metabolism: 15-hydroxyprostaglandin dehydrogenase. Prostaglandins Leukot Essent Fatty Acids 62, 1-5. doi: 10.1054/plef.1999.0117

Mitchell, M. D., Peiris, H. N., Kobayashi, M., Koh, Y. Q., Duncombe, G., Illanes, S. E., et al. (2015). Placental exosomes in normal and complicated pregnancy. Am. J. Obstetr. Gynecol. 213, S173-S181. doi: 10.1016/j.ajog.2015.07.001

Mitchell, M. D., Rice, G. E., Vaswani, K., Kvaskoff, D., and Peiris, H. N. (2016). Differential regulation of eicosanoid and endocannabinoid production by inflammatory mediators in human choriodecidua. PLoS One 11:e0148306. doi: 10.1371/journal.pone.0148306

Mouillet, J.-F., Ouyang, Y., Bayer, A., Coyne, C. B., and Sadovsky, Y. (2014). The role of trophoblastic microRNAs in placental viral infection. Int. J. Dev. Biol. 58, 281.

Narumiya, S., and Furuyashiki, T. (2011). Fever, inflammation, pain and beyond: prostanoid receptor research during these 25 years. FASEB J. 25, 813-818. doi: 10.1096/fj.11-0302ufm

Navajas, R., Corrales, F. J., and Paradela, A. (2019). Serum exosome isolation by size-exclusion chromatography for the discovery and validation of preeclampsia-associated biomarkers. Methods Mol. Biol. 1959, 39-50.

Ni, H., Sun, T., Ma, X.-H., and Yang, Z.-M. (2003). Expression and regulation of cytosolic prostaglandin E synthase in mouse uterus during the periimplantation period. Biol. Reprod. 68, 744-750.

Nielsen, M. R., Frederiksen-Møller, B., Zachar, R., Jørgensen, J. S., Hansen, M. R., Ydegaard, R., et al. (2017). Urine exosomes from healthy and hypertensive pregnancies display elevated level of $\alpha$-subunit and cleaved $\alpha$-and $\gamma$-subunits of the epithelial sodium channel-ENaC. Pflügers Arch. 469, 1107-1119.

Olson, D. M., and Ammann, C. (2007). Role of the prostaglandins in labour and prostaglandin receptor inhibitors in the prevention of preterm labour. Front. Biosci. 12:1329-1343. doi: 10.2741/2151

Patel, B., Elguero, S., Thakore, S., Dahoud, W., Bedaiwy, M., and Mesiano, S. (2015). Role of nuclear progesterone receptor isoforms in uterine pathophysiology. Hum. Reprod. Update 21, 155-173.

Patel, F. A., Funder, J. W., and Challis, J. R. (2003). Mechanism of cortisol/progesterone antagonism in the regulation of 15-hydroxyprostaglandin dehydrogenase activity and messenger ribonucleic acid levels in human chorion and placental trophoblast cells at term. J. Clin. Endocrinol. Metab. 88, 29222933. doi: 10.1210/jc.2002-021710

Peiris, H. N., Romero, R., Vaswani, K., Reed, S., Gomez-Lopez, N., Tarca, A. L., et al. (2019). Preterm labour is characterized by a high abundance of amniotic fluid prostaglandins in patients with intra-amniotic infection or sterile intraamniotic inflammation. J. Matern. Fetal Neonatal Med. doi: 10.1080/14767058. 2019.1702953 [Epub ahead of print].

Peiris, H. N., Vaswani, K., Almughlliq, F., Koh, Y. Q., and Mitchell, M. D. (2017). Review: eicosanoids in preterm labour and delivery: Potential roles of exosomes in eicosanoid functions. Placenta 54, 95-103. doi: 10.1016/j.placenta.2016.12. 013

Peiris, H. N., Vaswani, K., Holland, O., Koh, Y. Q., Almughlliq, F. B., Reed, S., et al. (2020). Altered productions of prostaglandins and prostamides by human amnion in response to infectious and inflammatory stimuli identified 
by mutliplex mass spectrometry. Prostaglandins Leukot. Essential Fatty Acids 154:102059.

Pillay, P., Maharaj, N., Moodley, J., and Mackraj, I. (2016). Placental exosomes and pre-eclampsia: maternal circulating levels in normal pregnancies and, early and late onset pre-eclamptic pregnancies. Placenta 46, 18-25.

Pillay, P., Moodley, K., Moodley, J., and Mackraj, I. (2017). Placenta-derived exosomes: potential biomarkers of preeclampsia. Int. J. Nanomed. 12, 80098023. doi: $10.2147 /$ IJN.S142732

Pomini, F., Patel, F. A., Mancuso, S., and Challis, J. R. (2000). Activity and expression of 15-hydroxyprostaglandin dehydrogenase in cultured chorionic trophoblast and villous trophoblast cells and in chorionic explants at term with and without spontaneous labour. Am. J. Obstet. Gynecol. 182(Pt 1), 221-226. doi: 10.1016/s0002-9378(00)70516-3

Powe, C. E. (2017). Early pregnancy biochemical predictors of gestational diabetes mellitus. Curr. Diabetes Rep. 17:12.

Rauk, P. N., and Chiao, J. P. (2000). Interleukin-1 stimulates human uterine prostaglandin production through induction of cyclooxygenase-2 expression. Am. J. Reprod. Immunol. 43, 152-159.

Record, M. (2014). Intercellular communication by exosomes in placenta: a possible role in cell fusion? Placenta 35, 297-302. doi: 10.1016/j.placenta.2014. 02.009

Record, M., Carayon, K., Poirot, M., and Silvente-Poirot, S. (2014). Exosomes as new vesicular lipid transporters involved in cell-cell communication and various pathophysiologies. Biochim. Biophys. Acta 1841, 108-120. doi: 10.1016/ j.bbalip.2013.10.004

Record, M., Silvente-Poirot, S., Poirot, M., and Wakelam, M. J. (2018). Extracellular vesicles: lipids as key components of their biogenesis and functions. J. Lipid Res. 59, 1316-1324.

Reinl, E. L., and England, S. K. (2015). Fetal-to-maternal signaling to initiate parturition. J. Clin. Invest. 125, 2569-2571.

Remes Lenicov, F., Rodriguez Rodrigues, C., Sabatté, J., Cabrini, M., Jancic, C., Ostrowski, M., et al. (2012). Semen promotes the differentiation of tolerogenic dendritic cells. J. Immunol. 189:4777. doi: 10.4049/jimmunol.1202089

Ricciotti, E., and FitzGerald, G. A. (2011). Prostaglandins and inflammation. Arterioscler. Thromb. Vasc. Biol. 31, 986-1000.

Romero, R., Espinoza, J., Gonçalves, L. F., Kusanovic, J. P., Friel, L. A., and Nien, J. K. (2006). Inflammation in preterm and term labour and delivery. Semin. Fetal Neonatal Med. 11, 317-326. doi: 10.1016/j.siny.2006. 05.001

Romero, R., Gonzalez, R., Baumann, P., Behnke, E., Rittenhouse, L., Barberio, D., et al. (1994a). Topographic differences in amniotic fluid concentrations of prostanoids in women in spontaneous labour at term. Prostaglandins Leukot. Essential Fatty Acids 50, 97-104.

Romero, R., Miranda, J., Chaemsaithong, P., Chaiworapongsa, T., Kusanovic, J. P., Dong, Z., et al. (2015). Sterile and microbial-associated intra-amniotic inflammation in preterm prelabour rupture of membranes. J. Matern. Fetal Neonatal Med. 28, 1394-1409. doi: 10.3109/14767058.2014.958463

Romero, R., Miranda, J., Chaiworapongsa, T., Korzeniewski, S. J., Chaemsaithong, P., Gotsch, F., et al. (2014). Prevalence and clinical significance of sterile intraamniotic inflammation in patients with preterm labour and intact membranes. Am. J. Reprod. Immunol. 72, 458-474. doi: 10.1111/aji.12296

Romero, R., Munoz, H., Gomez, R., Galasso, M., Sherer, D. M., Cotton, D., et al. (1994b). Does infection cause premature labour and delivery? Semin. Reprod. Endocrinol. 17, 12-19.

Romero, R., Munoz, H., Gomez, R., Parra, M., Polanco, M., Valverde, V., et al. (1996). Increase in prostaglandin bioavailability precedes the onset of human parturition. Prostaglandins Leukot. Essential Fatty Acids 54, 187-191.

Saez, T., de Vos, P., Sobrevia, L., and Faas, M. M. (2018). Is there a role for exosomes in foetoplacental endothelial dysfunction in gestational diabetes mellitus? Placenta 61, 48-54. doi: 10.1016/j.placenta.2017.11.007

Salomon, C., Torres, M. J., Kobayashi, M., Scholz-Romero, K., Sobrevia, L., Dobierzewska, A., et al. (2014). A gestational profile of placental exosomes in maternal plasma and their effects on endothelial cell migration. PLoS One 9:e98667. doi: 10.1371/journal.pone.0098667

Samuelsson, B. (1963). Isolation and identification of prostaglandins from human seminal plasma 18. Prostaglandins and related factors. J. Biol. Chem. 238, 3229-3234.
Sarker, S., Scholz-Romero, K., Perez, A., Illanes, S. E., Mitchell, M. D., Rice, G. E., et al. (2014). Placenta-derived exosomes continuously increase in maternal circulation over the first trimester of pregnancy. J. Transl. Med. 12:204. doi: 10.1186/1479-5876-12-204

Shao, H., Im, H., Castro, C. M., Breakefield, X., Weissleder, R., and Lee, H. (2018). New technologies for analysis of extracellular vesicles. Chem. Rev. 118, 1917-1950. doi: 10.1021/acs.chemrev.7b00534

Sheller-Miller, S., and Menon, R. (2020). Isolation and characterization of human amniotic fluid-derived exosomes. Methods Enzymol. 645, 181-194.

Slater, D., Dennes, W., Sawdy, R., Allport, V., and Bennett, P. (1999). Expression of cyclo-oxygenase types-1 and -2 in human fetal membranes throughout pregnancy. J. Mol. Endocrinol. 22, 125-130. doi: 10.1677/jme.0.0220125

Smith, W. L. (1989). The eicosanoids and their biochemical mechanisms of action. Biochem. J. 259, 315-324. doi: 10.1042/bj2590315

Smith, W. L., DeWitt, D. L., and Garavito, R. M. (2000). Cyclooxygenases: structural, cellular, and molecular biology. Annu. Rev. Biochem. 69, 145-182.

Smith, W. L., Garavito, R. M., and DeWitt, D. L. (1996). Prostaglandin endoperoxide $\mathrm{H}$ synthases (cyclooxygenases)-1 and -2. J. Biol. Chem. 271, 33157-33160. doi: 10.1074/jbc.271.52.33157

Solano, M. E., and Arck, P. C. (2020). Steroids, pregnancy and fetal development [Review]. Front. Immunol. 10:3017. doi: 10.3389/fimmu.2019.03017

Steetskamp, J., Bachmann, E., Hasenburg, A., and Battista, M. J. (2020). Safety of misoprostol for near-term and term induction in small-for-gestational-age pregnancies compared to dinoprostone and primary cesarean section: results of a retrospective cohort study. Arch. Gynecol. Obstet. 302, 1369-1374.

Strauss, J. F., and FitzGerald, G. A. (2019). "Chapter 4 - steroid hormones and other lipid molecules involved in human reproduction," in Yen and Jaffe's Reproductive Endocrinology (Eighth Edition), eds J. F. Strauss and R. L. Barbieri (Amsterdam: Elsevier), 75-114e117. doi: 10.1016/B978-0-323-47912-7.00 004-4

Subra, C., Grand, D., Laulagnier, K., Stella, A., Lambeau, G., Paillasse, M., et al. (2010). Exosomes account for vesicle-mediated transcellular transport of activatable phospholipases and prostaglandins. J. Lipid Res. 51, 21052120.

Sugimoto, Y., Yamasaki, A., Segi, E., Tsuboi, K., Aze, Y., Nishimura, T., et al. (1997). Failure of parturition in mice lacking the prostaglandin F receptor. Science 277, 681-683. doi: 10.1126/science.277.5326.681

Szczykutowicz, J., Kałuża, A., Kaźmierowska-Niemczuk, M., and FerensSieczkowska, M. (2019). The potential role of seminal plasma in the fertilization outcomes. BioMed Res. Int. 2019:5397804. doi: 10.1155/2019/5397804

Thomas, J., Fairclough, A., Kavanagh, J., and Kelly, A. J. (2014). Vaginal prostaglandin (PGE2 and PGF2a) for induction of labour at term. Cochrane Database Syst. Rev. 2014:Cd003101. doi: 10.1002/14651858.CD003101.pub3

Triggs, T., Kumar, S., and Mitchell, M. (2020). Experimental drugs for the inhibition of preterm labour. Expert Opin. Invest. Drugs 29, 507-523.

Truong, G., Guanzon, D., Kinhal, V., Elfeky, O., Lai, A., Longo, S., et al. (2017). Oxygen tension regulates the miRNA profile and bioactivity of exosomes released from extravillous trophoblast cells-liquid biopsies for monitoring complications of pregnancy. PLoS One 12:e0174514. doi: 10.1371/journal.pone. 0174514

Ueno, N., Takegoshi, Y., Kamei, D., Kudo, I., and Murakami, M. (2005). Coupling between cyclooxygenases and terminal prostanoid synthases. Biochem. Biophys. Res. Commun. 338, 70-76. doi: 10.1016/j.bbrc.2005.08.152

Vijayakumar, R., and Walters, W. A. (1983). Human luteal tissue prostaglandins, $17 \beta$-estradiol, and progesterone in relation to the growth and senescence of the corpus luteum. Fertil. Steril. 39, 298-303.

von Linsingen, R., Bicalho, M. D. G., and de Carvalho, N. S. (2017). Baby born too soon: an overview and the impact beyond the infection. J. Matern. Fetal Neonatal Med. 30, 1238-1242. doi: 10.1080/14767058.2016.1209653

Welch, B. M., Keil, A. P., van 't Erve, T. J., Deterding, L. J., Williams, J. G., Lih, F. B., et al. (2020). Longitudinal profiles of plasma eicosanoids during pregnancy and size for gestational age at delivery: a nested case-control study. PLoS Med. 17:e1003271. doi: 10.1371/journal.pmed.1003271

Woodward, D. F., Jones, R. L., and Narumiya, S. (2011). International union of basic and clinical pharmacology. LXXXIII: classification of prostanoid receptors, updating 15 years of progress. Pharmacol. Rev. 63, 471-538. doi: $10.1124 /$ pr.110.003517 
Yang, H., Ma, Q., Wang, Y., and Tang, Z. (2020). Clinical application of exosomes and circulating microRNAs in the diagnosis of pregnancy complications and foetal abnormalities. J. Transl. Med. 18:32. doi: 10.1186/s12967-020-02227-w

Yoon, B. H., Romero, R., Moon, J. B., Shim, S. S., Kim, M., Kim, G., et al. (2001). Clinical significance of intra-amniotic inflammation in patients with preterm labour and intact membranes. Am. J. Obstet. Gynecol. 185, 1130-1136. doi: 10.1067/mob.2001.117680

Yu, Y., Cheng, Y., Fan, J., Chen, X.-S., Klein-Szanto, A., Fitzgerald, G. A., et al. (2005). Differential impact of prostaglandin $H$ synthase 1 knockdown on platelets and parturition. J. Clin. Invest. 115, 986-995. doi: 10.1172/JCI23683

Zhang, Y., Liu, Y., Liu, H., and Tang, W. H. (2019). Exosomes: biogenesis, biologic function and clinical potential. Cell Biosci. 9:19. doi: 10.1186/s13578-0190282-2
Conflict of Interest: The authors declare that the research was conducted in the absence of any commercial or financial relationships that could be construed as a potential conflict of interest.

The handling editor declared a past co-authorship with one of the authors MM.

Copyright (C) 2020 Mosaad, Peiris, Holland, Morean Garcia and Mitchell. This is an open-access article distributed under the terms of the Creative Commons Attribution License (CC BY). The use, distribution or reproduction in other forums is permitted, provided the original author(s) and the copyright owner(s) are credited and that the original publication in this journal is cited, in accordance with accepted academic practice. No use, distribution or reproduction is permitted which does not comply with these terms. 